\title{
Uji Toksisitas Akut Ekstrak dan Fraksi Kulit Batang Ketapang Laut (Terminalia Catappa L.) menggunakan Metode BSLT
}

\section{(Acute Toxicity Test of Extract and Fractions Terminalia Catappa L. Stem Skin with BSLT Method)}

\author{
Ari Sartinah ${ }^{1 *}$, Yamin ${ }^{1}$, Nurhasanah ${ }^{1}$, Muhammad Arba ${ }^{1}$, Nur Illiyyin Akib ${ }^{1}$, Andi Nafisah Tendri \\ Adjeng $^{1}$
}

${ }^{1}$ Fakultas Farmasi Universitas Halu Oleo, Kampus Hijau Bumi Tridharma, Jl. HEA Mokodompit Kendari 93232

E-mail: sartinahari@gmail.com

\author{
Article Info: \\ Received: 12 March 2020 \\ Accepted: 12 April 2020 \\ DOI: \\ 10.33772/pharmauho.v6i \\ 1.11430
}

\begin{abstract}
Acute toxicity is the ability of chemical (drug / drug ingredient) to cause damage to organisms in relatively short time. The purpose of this study was to determine the potential for acute toxicity of methanol extract, ethyl acetate and water fractions of sea ketapang stem skin (Terminalia catappa L.). Acute toxicity testing was performed using the BSLT (Brine Shrimp Lethality Test) method and program analysis to determine the $\mathrm{LC}_{50}$ values of extracts and fractions. The results of the acute toxicity test showed the $\mathrm{LC}_{50}$ values of methanol extract, ethyl acetate and water fractions of the plant stem skin consecutively were $247,997 \mathrm{ppm} ; 400,666$ $\mathrm{ppm}$ and $618,046 \mathrm{ppm}$. This shows that the methanol extract of sea ketapang stems (Terminalia catappa L.) is the most toxic compared to the ethyl acetate and the water fraction.
\end{abstract}

Keywords: Extract, Fraction, Terminalia catappa L., BSLT, Artemia salina Leach

\begin{abstract}
Abstrak
Toksisitas akut merupakan kemampuan suatu bahan kimia (obat/bahan obat) dalam menimbulkan kerusakan pada suatu organisme dalam waktu yang relatif singkat. Tujuan penelitian ini adalah untuk mengetahui potensi ketoksikan akut dari ekstrak metanol, fraksi etil asetat dan fraksi air kulit batang ketapang laut (Terminalia catappa L.). Pengujian toksisitas akut dilakukan dengan menggunakan metode BSLT (Brine Shrimp Lethality Test) dan menggunakan analisis program untuk mengetahui nilai $\mathrm{LC}_{50}$ dari ekstrak dan fraksi. Hasil uji toksisitas akut menunjukan nilai $\mathrm{LC}_{50}$ dari ekstrak metanol, fraksi etil asetat dan fraksi air kulit batang ketapang laut (Terminalia catappa L. ) berturut-turut $247,997 \mathrm{ppm} ; 400,666 \mathrm{ppm}$ dan 618,046 ppm. Hal ini menunjukan bahwa ekstrak metanol batang ketapang laut (Terminalia catappa L.) bersifat paling toksik dibandingkan fraksi etil asetat dan fraksi air.
\end{abstract}

Kata kunci: Ekstrak, Fraksi, Terminalia catappa L., BSLT, Artemia salina Leach

\section{Pendahuluan}

Ketapang laut (Terminalia catappa L.) merupakan salah satu tumbuhan obat yang banyak tumbuh di Indonesia dan telah digunakan secara tradisional untuk mengobati penyakit kardiovaskuler, kulit, liver, pernafasan, perut, gonorrhoea, antijamur, dan insomnia [1]. Khasiat tanaman ketapang ini tidak lepas dari senyawa yang terkandung di dalam tanaman ketapang itu sendiri. Ketapang diketahui mengandung senyawa obat seperti flavonoid, triterpenoid, tanin, alkaloid, steroid dan asam lemak. Jika dilihat dari kandungan senyawa pada kulit batang ketapang, ada kemungkinan senyawa-senyawa tersebut mempunyai aktivitas toksik [2]. Ketoksikan suatu obat/bahan obat perlu dilakukan sebagai uji pendahuluan dalam mengamati aktifitas farmaklogis untuk dilanjutkan uji farmakologi lainnya dan sebagai informasi tentang keamanannya $[3,4]$. Oleh sebab itu, perlu dilakukan 
penelitian uji toksisitas akut dengan menggunakan metode BSLT (Brine Shrimp Lethality Test)

Brine Shirmp Lethality Test (BSLT) merupakan uji pendahuluan yang mengarah pada uji aktivitas toksik senyawa metabolit sekunder menggunakan larva udang Artemia salina Leach sebagai hewan uji. Aktivitas toksik diketahui dari jumlah kematian larva A. salina Leach karena pengaruh ekstrak atau senyawa bahan alam pada konsentrasi yang diberikan $[5,6]$. Tingkat toksisitas suatu ekstrak berdasarkan $\mathrm{Lc}_{50}$, yaitu kategori sangat tinggi (highly toxic) apabila mampu membunuh $50 \%$ larva pada konsentrasi $0-100 \mu \mathrm{g} / \mathrm{ml}$, sedang (medium toxic) pada konsentrasi 100-500 $\mu \mathrm{g}$ $/ \mathrm{ml}$, rendah (low toxic) pada konsentrasi 500-1000 $\mu \mathrm{g} / \mathrm{ml}$ dan tidak toksik (non toxic) pada konsentrasi > $1000 \mu \mathrm{g} / \mathrm{ml}[7]$.

Penelitian tentang tanaman ketapang laut (Terminalia catappa L.) khususnya untuk penelitian tentang kulit batang ketapang laut masih sangatlah terbatas. Oleh karena itu perlu dilakukan uji toksisitas akut ekstrak metanol dan fraksi kulit batang ketapang laut terhadap Artemia salina L. dengan metode Brine Shrimp Lethaly Test (BSLT) yang dapat menjadi informasi awal dalam pengembangan alternatif obat herbal.

\section{Metode}

\subsection{Pembuatan Ekstrak dan Fraksi}

\subsubsection{Penyiapan Sampel}

Sampel kulit batang ketapang laut (Terminalia catappa L.) diperoleh dari Kota Raha, Sulawesi Tenggara. Kulit batang segar disortasi basah, selanjutnya dilakukan pengupasan kulit bagian luar dan bilas dengan air bersih mengalir[8]. Sampel kemudian dirajang dan dikeringkan dengan cara dijemur dibawah sinar matahari. Selanjutnya, sampel yang telah kering disortasi kering dan dihaluskan menggunakan blender hingga diperoleh serbuk simplisia kering selanjutnya siap diekstraksi[9].

\subsubsection{Pembuatan Ekstrak Metanol}

Serbuk simplisia kulit batang ketapang laut (Terminalia catappa L.) yang ditimbang sebanyak 700 gram kemudian dimasukkan dalam wadah dan diekstraksi secara maserasi selama 3 x 24 jam dengan menggunakan pelarut metanol sambil sesekali diaduk, kemudian disaring. Filtrat yang diperoleh dikumpulkan dan dipekatkan dengan ratory evaporator sampai diperoleh ekstrak kental [10].

\subsubsection{Skrinning fitokimia}

Sebanyak 1 gram ekstrak dan fraksi kulit batang ketapang laut dan dilarutkan dalam $10 \mathrm{~mL}$ pelarut masing-masing ektrak. Tahap pengindetifikasian dari senyawa senyawa metabolit sekunder mengunakan metode tabung yang terdiri atas:

\section{Uji alkaloid}

Sebanyak $1 \mathrm{~mL}$ sampel dimasukkan ke dalam tabung reaksi kemudian ditetesi dengan pereaksi dragendorff sebanyak 2-3 tetes. Adanya senyawa alkaloid ditunjukkan dengan terbentuknya endapan merah bata. Jika menggunakan perekasi meyer, maka sebanyak $1 \mathrm{~mL}$ sampel ditambahkan $1-3 \mathrm{~mL}$ pereaksi tersebut, endapan putih menunjukkan adanya senyawa alkaloid [11].

\section{Uji flavonoid}

Ekstrak metanol, fraksi etil asetat, dan fraksi air kulit batang ketapang laut dimasukan kedalam tabung reaksi sebanyak $1 \mathrm{~mL}$, dimasukan $0,1 \mathrm{~g}$ serbuk magnesium dan ditambahkan $\mathrm{HCl} 2 \mathrm{~mL}$ pekat. Terbentuk larutan berwarna merah menunjukan adanya flavonoid [12].

\section{Terpenoid}

Ekstrak metanol, fraksi etil asetat dan fraksi air kulit batang ketapang laut dimasukkan kedalam tabung reaksi sebanyak $1 \mathrm{~mL}$, dan ditambahkan 0,5 $\mathrm{mL}$ asam asetat anhidrat dan asam sulfat pekat sebanyak $2 \mathrm{~mL}$. Keberadaan terpenoid ditandai dengan terbentuknya warna cokelat [13].

\section{Saponin}

Ekstrak metanol, fraksi etil asetat dan fraksi air kulit batang ketapang laut dimasukkan kedalam tabung reaksi sebanyak $1 \mathrm{~mL}$, ditambahkan dengan 2 $\mathrm{mL}$ air panas kemudian didinginkan, dikocok kuat selama 10 detik. Terbentuk buih yang mantap selama tidak kurang dari 10 menit [12].

\section{Tanin}

Ekstrak metanol, fraksietil asetat dan fraksi air kulit batang ketapang laut dimasukkan dalam tabung reaksi sebanyak $1 \mathrm{~mL}$, ditambahkan dengan $1 \mathrm{~mL}$ larutan Fe (III) klorida 1\%. Jika terbentuk warna biru tua, biru kehitaman atau hitam kehijuan menunjukkan adanya senyawa tanin [13].

\subsubsection{Fraksinasi}

Sebanyak 15 gram ekstrak metanol batang ketapang laut (Terminalia catappa) dilarutkan dalam $300 \mathrm{~mL}$ air steril. Selanjutnya $100 \mathrm{~mL}$ ekstrak yang telah dilarutkan dimasukkan kedalam corong pisah, kemudian $100 \mathrm{~mL}$ pelarut $n$-heksan ditambahkan kedalam corong pisah untuk dilakukan pemisahan secara partisi dengan perbandingan 1:1 ekstrak dan pelarut. Corong pisah tersebut kemudian dikocok 
dengan kuat hingga tercampur dan didiamkan beberapa menit hingga memisah menjadi dua fraksi yaitu fraksi metanol dan fraksi $n$-heksan. Fraksi $n$ heksan kemudian dikeluarkan dari corong pisah sedangkan $100 \mathrm{~mL}$ fraksi metanol dipartisi kembali dengan $200 \mathrm{~mL}$ pelarut $n$-heksan dengan perbandingan yang berbeda yaitu perbandingan 1:2 fraksi metanol dan pelarut $n$-heksan. Setelah diperoleh fraksi metanol dan fraksi $n$-heksan, maka dilanjutkan dengan menggunakan pelarut etil asetat. Selanjutnya, fraksi metanol dipartisi kembali dengan pelarut etil asetat masing-masing sebanyak $100 \mathrm{~mL}$ dengan perbandingan 1:1 fraksi metanol dan pelarut etil asetat menggunakan corong pisah. Corong pisah dikocok kemudian didiamkan hingga terbentuk dua lapisan fraksi yaitu fraksi metanol dan fraksi etil asetat. Fraksi etil asetat dikeluarkan sedangkan fraksi metanol dipartisi kembali menggunakan pelarut etil asetat dengan perbandingan yang berbeda yaitu perbandingan 1:2 (fraksi metanol sebanyak $100 \mathrm{~mL}$ dan pelarut etil asetat sebanyak $200 \mathrm{~mL}$ ). Selanjutnya ekstrak dan fraksi ini masing-masing diuapkan menggunakan vacum rotary evaporator hingga didapatkan ekstrak dan fraksi kental [14].

\subsection{Uji Toksisitas Metode BSLT}

\subsubsection{Penetasan Larva udang Artemia salina Leach}

Penetasan telur A. salina dilakukan dengan cara merendam $50 \mathrm{mg}$ telur $A$. salina dalam wadah yang berisi air laut di bawah cahaya lampu 40 Watt. Telur A. salina menetas menjadi larava setelah 24 jam. Larva A. salina yang baik digunakan untuk uji BSLT yaitu yang berumur 48 jam sebab jika lebih dari 48 jam dikhawatirkan kematian $A$. salina bukan disebabkan toksisitas melainkan oleh terbatasnya persediaan makanan [15].

\subsubsection{Penyiapan Sampel Uji}

Masing-masing dibuat larutan stok 2000 ppm ekstrak metanol, fraksi etil asetat dan fraksi air kulit batang ketapang laut dengan cara melarutkan 0,2 gram ekstrak dalam air laut hingga mencapai volume 100 $\mathrm{mL}$. Blanko dibuat dengan cara diambil 2,5 ml DMSO kemudian ditambahkan air laut 2,5 ml Uji Toksisitas Metode BSLT.

Sebanyak 10 larva udang dalam 2,5 ml air laut dimasukan kedalam vial uji, kemudian ditambahkan 2,5 ml larutan sampel. Untuk setiap konsentrasi dilakukan 3 kali pengulangan. Sebagai kontrol pelarut dilakukan dengan 2,5 ml larutan blanko kemudian ditambahkan air laut 2,5 $\mathrm{ml}$ [16]. Pengujiannya dilakukan dengan menggunakan konsentrasi dengan 10 variasi konsentrasi yaitu 10 ppm, 25 ppm, 50 ppm
, 100 ppm, 125 ppm, 250 ppm, 500 ppm, 750 ppm, 1000 ppm, 2000 ppm.

\subsubsection{Perhitungan}

Pengamatan dilakukan setelah 24 jam dengan menghitung jumlah larva udang yang masih hidup dan yang sudah mati. Pengukuran mortalitas larva $A$. salina Leach[17]:

$$
\frac{\text { Mortalitas }(\%)=}{\frac{\text { Akumulasi mati }}{\text { Akumulasi mati+Akumulasi Hidup }} \times 100 \%}
$$

\subsubsection{Analisis Data}

Analisis probit antara konsentrasi uji dan jumlah kematian larva diuji dengan menggunakan Minitab ver.17.2.1 dapat menujukkan nilai $\mathrm{LC}_{50}$ dari masing-masing sampel [18].

\section{Hasil dan Pembahasan}

Skrining fitokimia dilakukan untuk memberikan gambaran tentang golongan senyawa yang terkandung dalam sampel kulit batang ketapang laut yang sedang diteliti secara kualitatif. Senyawa-senyawa tersebut dapat diidentifikasi dengan pereaksi-pereaksi yang mampu memberikan ciri khas dari setiap golongan dari metabolit sekunder. Identifikasi senyawa yang dilakukan terhadap ekstrak dan fraksi kulit batang ketapamg laut diantaranya alkaloid, flavonoid, tanin, saponin, dan terpenoid [19].

Tabel 1. Hasil skrining fitokimia ekstrak metanol dan fraksi etil asetat dan fraksi air kulit batang ketapang laut

\begin{tabular}{cccc}
\hline \multirow{2}{*}{$\begin{array}{c}\text { Senyawa } \\
\text { Fitokimia }\end{array}$} & \multicolumn{3}{c}{ Sampel } \\
\cline { 2 - 4 } & $\begin{array}{c}\text { Ekstrak } \\
\text { metanol }\end{array}$ & $\begin{array}{c}\text { Fraksi etil } \\
\text { asetat }\end{array}$ & $\begin{array}{c}\text { Fraksi } \\
\text { air }\end{array}$ \\
\hline Alkaloid & + & + & + \\
Flavonoid & + & + & + \\
Tanin & + & + & + \\
Saponin & - & - & - \\
Terpenoid & + & + & + \\
\hline
\end{tabular}

Kandungan senyawa metabolit skunder yang terdapat dalam Ekstrak methanol, fraksi etil asetat, dan fraksi air adalah sama yaitu mengandung alkaloid, flavonoid, tanin, dan terpenoid. Ekstrak dan kedua fraksi kulit batang ketapang laut tersebut tidak mengandung saponin

Uji toksisitas akut merupakan suatu pengujian untuk mendeteksi efek toksik suatu obat/bahan obat yang terjadi dalam waktu singkat setelah pemberian bahan uji dalam waktu 24 jam. Suatu ekstrak dan fraksi dikatakan toksik berdasarkan metode BSLT jika 
nilai $\mathrm{LC}_{50}<500$ ppm. $\mathrm{LC}_{50}$ atau Lethal Concentration $50 \%$ menyatakan besarnya kadar sample yang mampu menyebabkan kematian populasi $50 \%$. Semakin kecil nilai LC $_{50}$ maka semakin besar ketoksikannya. [20]. Berikut adalah nilai $\mathrm{LC}_{50}$ ekstrak dan fraksi kulit batang ketapang laut (Terminalia catappa L.) (Tabel 2.) .

Pada penelitian ini dilakukan uij toksisitas akut pada ekstrak methanol, fraksi etil asetat dan fraksi air. Masing-masing bahan uji memilki nilai $\mathrm{LC}_{50}$ yang berbeda. Berikut adalah nilai $\mathrm{LC}_{50}$ ekstrak methanol, fraksi etil asetat dan fraksi air kulit batang ketapang laut (Terminalia catappa L.).

Tabel. 2 Nilai LC $_{50}$ Ekstrak dan Fraksi Kulit Batang Ketapang Laut (Terminalia catappa L.)

\begin{tabular}{ccc}
\hline No & Sampel & LC50 (ppm) \\
\hline 1 & Ekstrak metanol & 247,997 \\
2 & Fraksi etil asetat & 400,666 \\
3 & Frasi Air & 618,046 \\
\hline
\end{tabular}

Berdasarkan tabel di atas terlihat bahwa ekstrak metanol memiliki nilai sebesar LC $_{50}$ sebesar 247,997 ppm, sementara fraksi etil asetat memilki nilai $\mathrm{LC}_{50}$ sebesar 400,666 ppm dan fraksi air sebesar 618,046 ppm dan. Hal ini menunjukkan bahwa ekstrak metanol dan fraksi etil asetat bersifat tosik nilai $\mathrm{LC}_{50}<500$ ppm.

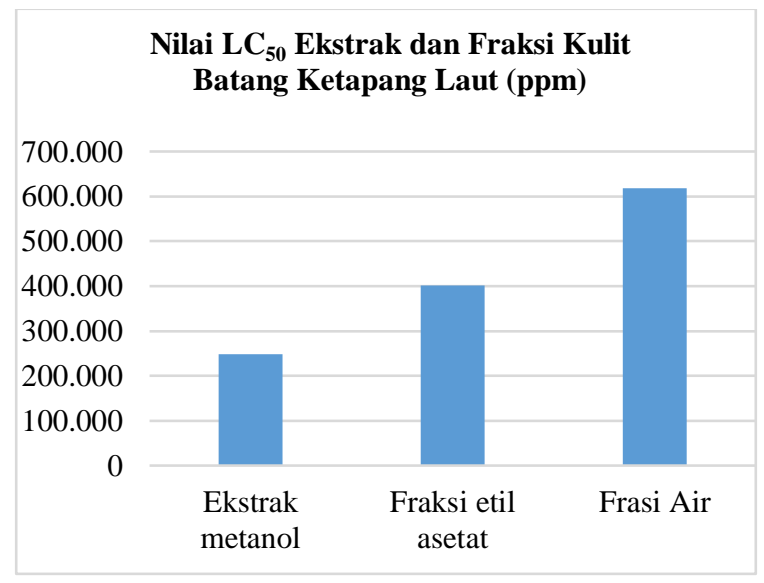

Gambar 1. Diagram Nilai LC L $_{50}$ Ekstrak dan Fraksi Kulit Batang Ketapang Laut (Terminalia catappa L.)

Dari grafik di atas menunjukkan bahwa ekstrak metanol memiliki nilai LC $_{50}$ paling rendah $(247,997$ ppm) dibandingkan fraksi etil asetat (400,666 ppm) dan fraksi air (618,046 ppm). Hal menunjukan bahwa ekstrak metanol lebih toksik dibandingkan fraksifraksi lainnya yaitu fraksi etil asetat dan fraksi air. Hal ini disebabkan karena pada ekstrak metanol lebih banyak terkandung senyawa yang bersifat polar, semipolar dan non polar. Senyawa-senyawa tersebut bekerja secara sinergis sehingga memliki kemampuan toksisitas yang paling tinggi dibandingkan dengan fraksi yang sudah dipisahkan senyawa-senyawanya berdasarkan tingkat kepolarnnya. Diperkirakan perbedaan jenis dan kadar metabolit sekunder yang terekstraksi tersebut sebanding dengan toksisitasnya [21].

Kandungan fenol, flavonoid, alkaloid, tanin dan terpenoid dalam kulit batang ketapang laut (Terminalia catappa L.) dapat memiliki aktivitas biologi. Secara umum senyawa fenolik pada konsentrasi tinggi bertindak sebagai toksin bagi plasma dengan merusak sistem dinding sel, sedangkan pada konsentrasi rendah dapat menghambat multiplikasi enzim in vitro [22]. Keberadaan senyawa metabolit sekunder dalam tanaman dapat dimanfaatkan sebagai agen biolarvasida dan antikanker [23]. Ekstrak metanol dan fraksi etil asetat kulit batang ketapang laut mempunyai potensi toksisitas. Hal tersebut berkaitan dengan senyawa yang terdapat dalam kulit batang ketapang laut yaitu alkaloid, terpenoid, tannin dan flavonoid, dimana pada kadar tertentu memiliki potensi toksisitas serta dapat menyebabkan kematian larva [24]. Cara kerja senyawa-senyawa tersebut adalah dapat bertindak sebagai racun perut (stomach poisoning) yang mengganggu alat penceraan larva dan menghambat reseptor perasa pada mulut larva. Akibatnya larva gagal mendapatkan stimulus rasa sehingga tidak mampu mengenali makanannya yang kemudian menyebabkan kematian larva Artemia Salina L [25].

\section{Kesimpulan}

Ekstrak metanol kulit batang ketapang laut (terminalia catappa L.) memiliki tingkat toksisitas yang paling tinggi dibandingkan dalam bentuk fraksinya (fraksi etil asetat dan fraksi air) dengan nilai LC50 sebesar 247,997 ppm.

\section{Ucapan Terima Kasih}

Ucapan terima kasih kepada Fakultas Farmasi Universitas Halu Oleo atas dukungan dan bantuan dalam pelaksanaan penelitian ini.

\section{Daftar Pustaka}

1. Nurrani, L.; Kinho, J.; Tabba, S. Active Ingredients and Their Toxicity of Several Forest Plant Species Indigenous from North Sulawesi 
Potential as Efficacious Medicine. J. Penelit. Has. Hutan, 2014, 32 (2), 123-138.

2. Chasani, M.; Fitriaji, R. B.; Purwati. Fraksinasi Ekstrak Metanol Kulit Batang Ketapang (Terminalia Catappa Linn.) Dan Uji Toksisitasnya Dengan Metode BSLT (Brine Shrimp Lethality Test) Moch. Molekul, 2013, 8 (1), 89-100.

3. Braguini, W. L.; Pires, N. V.; Alves, B. B. Phytochemical Analysis, Antioxidant Properties and Brine Shrimp Lethality of Unripe Fruits of Solanum Viarum. J. Young Pharm., 2018, 10 (2), 159-163. https://doi.org/10.5530/jyp.2018.10.36.

4. Hamsidi, R.; Wahyuni; Sani, A. Uji Toksisitas Akut Ekstrak Metanol Daun Keji Beling ( Strobilanthes Crispus BI .), Batang Dan Bunga Jarak Tintir ( Jatropha Multifida L .) Terhadap Larva Artemia Salina Leach Dengan Metode Brine Shrimp Lethality Test ( BSLT ). Pharmauho, 2014, 1 (1), 12-15.

5. Meyer, B. N.; Ferrigni, N. R.; Putnam, J. E. Brine Shrimp: A Convenient General Bioassay for Active Plant Constituents. Planta Med., 1982, 45 (1), 31-34. https://doi.org/10.1055/s-2007971236.

6. Baud, G. S.; Sangi, M. S.; Koleangan, H. S. J. Analisis Senyawa Metabolit Sekunder Dan Uji Toksisitas Ekstrak Etanol Batang Tanaman Patah Tulang (Euphorbia Tirucalli L.) Dengan Metode Brine Shrimp Lethality Test (BSLT). J. Ilm. Sains, 2014, 14 (2), 106-112.

7. Eav Susanty Simaremare. Skrining Fitokimia Ekstrak Etanol Daun Gatal (Laportea Decumana (Roxb) Wedd). Pharmacy, 2014, 11 (01), 98-107.

8. Obat, B. P.; Indonesia, M. R. Penyiapan Simplisia Untuk Sediaan Herbal; Jakarta: BPOM RI, 2005.

9. Yamin; Hasnawati. Potensi Ekstrak Daun Dan Batang Katola ( Arcangelisia Flava L . Merr ) Sebagai Antimikroba. Pharmauho, 2017, 3 (2), 23-27.

10. Mappasomba, M.; Wirasmanto, B.; Malaka, M. H. Penapisan Fitokimia Dan Uji Toksisitas Akut Ekstrak Metanol Beberapa Tanaman Obat Terhadap Larva Udang Artemia Salina Leach. Pharmauho, 2019, 5 (September), 30-34.

11. Khadijah, K.; Jayali, A. M.; Umar, S.; Sasmita, I. Penentuan Total Fenolik Dan Aktivitas Antioksidan Ekstrak Etanolik Daun Samama (Anthocephalus Macrophylus) Asal Ternate, Maluku Utara. J. Kim. Mulawarman, 2017, 15 (1), 11-18.

12. Simaremare, E. S. Skrining Fitokimia Ekstrak Etanol Daun Gatal (Laportea Decumana (Roxb.) Wedd). Pharm. J. Farm. Indones. (Pharmaceutical J. Indones., 2014, 11 (1).
13. Adriyadi, D.; Arreneuz, S.; Wibowo, M. A. Skrining Fitokimia Dan Uji Aktivitas Antioksidan Ekstrak Metanol Kulit Batang Lembawang (Mangifera Sp.). J. Kim. Khatulistiwa, 2016, 5 (2), 1-5.

14. Wahdaningsih, S.; Setyowati, E. P.; Wahyuono, S. Aktivitas Penangkap Radikal Bebas Dari Batang Pakis ( Alsophila Glauca J . Sm ). Maj. Obat Tradis., 2011, 16 (3), 156-160.

15. Sondakh, R. M.; Posangi, J.; Wowor, P. M. Uji Toksisitas Akut Ekstrak Spons Laut (Callyspongia Aerizusa) Terhadap Larva Artemia Salina Leach Dengan Metode Brine Shrimp Lethality Test. J. e-Biomedik, 2017, 5 (2), 0-3. https://doi.org/10.35790/ebm.5.2.2017.18312.

16. Frengki, R.; Pertiwi, D. Uji Toksisitas Ekstrak Etanol Sarang Semut Lokal Aceh (Mymercodia Sp.) Dengan Metode BSLT Terhadap Larva Udang Artemia Salina Leach. J. Med. Vet., 2014, $8(1), 60-62$.

17. Metanol, E.; Djamil, R.; Anelia, T. Penapisan Fitokimia, Uji BSLT, Dan Uji Antioksidan. J. Ilmu Kefarmasian Indones., 2009, 7 (2), 65-71.

18. Masriyono; Afrianisa, A. D. R. R. D. Uji Toksisitas LC50 Air Limbah Restoran Cepat Saji Terhadap Biota Uji Ikan Nila Melalui Analisa Probabilitas Menggunakan Software Minitab. In Seminar Teknologi Perencanaan, Perancangan, Lingkungan, dan Infrastruktur; 2019; pp 459464.

19. Adjeng, A. N. T.; Hairah, S.; Herman, S.; Ruslin, R.; Fitrawan, L. O. M.; Sartinah, A.; Ali, N. F. M.; Sabarudin, S. Skrining Fitokimia Dan Evaluasi Sediaan Sabun Cair Ekstrak Etanol 96\% Kulit Buah Salak Pondoh (Salacca Zalacca (Gaertn.) Voss.) Sebagai Antioksidan. Pharmauho J. Farm. Sains, dan Kesehat., 2020, 5 (2), 3-6. https://doi.org/10.33772/pharmauho.v5i2.10170.

20. R. Hamidi, M.; Jovanova, B.; Kadifkova Panovska, T. Toxicological Evaluation of the Plant Products Using Brine Shrimp (Artemia Salina L.) Model. Maced. Pharm. Bull., 2014, 60 (01), 9-18.

21. Lisdawati, V.; Wiryowidagdo, S.; Kardono, L. B. S. Brine Shrimp Lethality Test (BSLT) Dari Berbagai Fraksi Ekstrak Daging Buah Dan Kulit Biji Mahkota Dewa (Phaleria Macrocarpa). Bul. Penelit. Kesehat., 2006, 34 (3), 111-118.

22. Puspitasari, E. Uji Toksisitas Dengan Menggunakan Metode Brine Shrimp Lethality Test (Bslt) Pada Ekstrak Mangrove (Avicennia Marina, Rhizophora Mucronata, Sonneratia Alba Dan Xylocarpus Granatum) Yang Berasal Dari Banyuasin, Sumatera Selatan. J. Biol. Trop., 
2018, 18 (1), 91-103.

23. Panggabean, L.; Nurhamidah, N.; Dewi, H. Profil Fitokimia Dan Uji Sitotoksik Ekstrak Etanol Tumbuhan Andaliman (Zanthoxylum Acanthopodium DC) Menggunakan Metode BSLT, Universitas Bengkulu, 2019.

24. Khanna, V. G.; Kannabiran, K. Sylvestre , and Eclipta Prostrata against Culex Qinquifaciatus
Mosquito Larvae. African J. Biotechnol., 2007, 6 (3), 307-311.

25. Susanah Rita, W.; Suirta, I.; Sabikin, A. Isolasi Dan Identifikasi Senyawa Yang Berpotensi Sebagai Antitumor Pada Daging Buah Pare (Momordica Charantia L.). J. Kim., 2008, 2 (1), $1-6$.

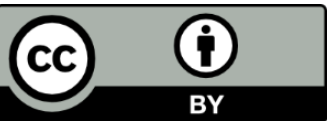

(C) 2020 by the authors; This article is an open access article distributed under the terms and conditions of the Creative Commons Attribution License (http://creativecommons.org/licenses/by/4.0/) 